\title{
AÇÚCAR E CAFÉ: AMBIGUIDADE DE RAízES DO BRASIL'
}

\author{
Monica Isabel de Moraes ${ }^{a}$
}

aDoutoranda em Sociologia pela Faculdade de Filosofia, Letras e Ciências Humanas da Universidade de São Paulo.São Paulo,SP,Brasil.E-mail: monica.moraes@usp.br

Orcid: 0000-0002-5446-1182

Luiz Carlos Jackson ${ }^{b}$

- Professor do Departamento de Sociologia, na Faculdade de Filosofia, Letras e Ciências Humanas

da Universidade de São Paulo. São Paulo, SP, Brasil. E-mail: ljackson@usp.br

Orcid: 0000-0002-6269-6096

http://dx.doi.org/10.1590/0102-325352/113

\section{Introdução}

Raizes do Brasil foi publicado em 1936, como primeiro volume da coleção Documentos Brasileiros, pela Editora José Olympio. Em 1948 saiu a segunda edição, bastante alterada, conforme reconhecido no prefácio por Sérgio Buarque de Holanda. Em 1956, a terceira, pela mesma editora, e em 1963, a quarta, integrando a coleção Biblioteca Básica Brasileira da Editora da Universidade de Brasília. Assim, entre 1936 e 1963, foram quatro edições, com intervalo médio de sete anos entre elas. A quinta edição (1969) pode ser entendida como uma viragem, uma vez que, acrescido do prefácio de Antonio Candido, "O significado de Raízes do Brasil", o livro ganhou um ritmo de publicação muito maior. Entre a quinta e a vigésima quinta (1993), todas

\footnotetext{
1 Agradecemos ao Núcleo de Sociologia da Cultura da USP pelo diálogo frutífero, especialmente, as sugestões de Darlan Praxedes Barbosa, Dimitri Pinheiro Silva, Lidiane Soares Rodrigues e Marcello Stella, assim como às/aos pareceristas anônimas/ os pelos comentários ao artigo, que nos permitiram aperfeiçoar nosso argumento.
} 
pela José Olympio, a média chegou a quase uma edição ao ano. Em 1996, saiu a vigésima-sexta, já pela Companhia das Letras, com quarenta e uma reimpressões até a vigésima-sétima edição, de 2014. Consideradas as reimpressões, o ritmo de produção do livro praticamente dobrou, com a média de duas fornadas por ano, além da "edição comemorativa" dos setenta anos do livro, de 2006, e da "edição crítica", por ocasião dos oitenta anos, de 2016.

Esse resumo da história editorial da obra, facilitado pela “Cronologia de Raízes do Brasil’, incluído na edição crítica de 2016, sugere a importância do sucesso editorial como índice de consagração, em especial, dos ensaios de interpretação do Brasil. Além disso, reforça que a quinta edição foi uma inflexão decisiva nessa história. Nossa hipótese, a respeito, é que isso se deu em função da leitura política da obra por Antonio Candido, no início da ditadura militar, que incorporou ao livro uma orientação progressista explícita e o constituiu em um libelo em favor da democracia no Brasil. ${ }^{2}$ Antes disso, as principais interpretações do ensaio não enfatizaram sua mensagem política. Esse significado condicionou o êxito posterior da obra.

A primeira edição de Raízes do Brasil, de 1936, teve ampla repercussão na imprensa, em grande medida porque o livro inaugurou a coleção Documentos Brasileiros, e em função do esquema forte de distribuição e divulgação implementado por José Olympio em sua editora (Sorá, 2010). Foram publicadas pelo menos 77 resenhas entre 1936 e $1938^{3}$ em diversos jornais do país, mas poucas discutiram os argumentos políticos do livro, que não deram o tom de sua recepção imediata.

\footnotetext{
2 Essa interpretação seria depois reiterada por Antonio Candido nos textos Sérgio em Berlim e depois (1982) e Radicalismos (1990).

3 Esse número corresponde às resenhas colecionadas por Cecília Buarque de Holanda, irmã do autor, disponíveis no Fundo Sergio Buarque de Holanda, mantido pelo Siarq/Unicamp.
} 
Por ocasião da segunda edição, o número de resenhas foi bem menor, mas contou com uma análise especializada, por meio da resenha publicada por Florestan Fernandes na Revista do Arquivo Municipal (n. 122, 1949). Embora atento à discussão política do livro, o então jovem sociólogo paulista tampouco enfatizou esse aspecto da obra. O tom geral de sua análise recaiu sobre o perfil ensaístico do livro, contra o qual o sociólogo se indispunha, reivindicando em contraponto a sociologia como ciência (Blanco; Jackson, 2014; Jackson, 2007). Vale notar que o resenhista avaliou as duas edições e defendeu que "a fisionomia do livro" (Fernandes, 1949, p. 223) havia se mantido.

A terceira edição (1956) foi resenhada pela socióloga Maria Isaura Pereira de Queiroz (1957), que avaliou o ensaio de maneira bastante favorável. ${ }^{4}$ Como Florestan, Maria Isaura não evidenciou as ideias de natureza política postas em discussão por Sérgio Buarque. ${ }^{5}$

A avaliação ligeira do livro por Dante Moreira Leite na primeira edição de O caráter nacional brasileiro (1954) quase não o discute também em termos políticos. O autor apenas o faz na segunda edição (1969), bastante modificada, na qual, apesar de enfatizar que "o seu objetivo é fundamentalmente político” (Leite, 1983, p. 318), não identifica uma direção unívoca ao posicionamento de Sérgio Buarque,

\footnotetext{
4 "Raramente é alcançado um diagnóstico tão profundo da psicologia de um povo como o deste livro. Colocando o problema da adequação da mentalidade ao 'estilo de vida', situa-se na convergência de duas disciplinas, a psicologia social e a antropologia cultural, e como se dá frequentemente com obras assim colocadas em zonas limítrofes, é um magnífico suscitador de hipóteses para o estudo da realidade brasileira tanto no passado como no presente" (Queiroz, 1957, p. 48)

${ }^{5}$ Levando em conta que a segunda edição foi resenhada por Florestan, a terceira por Maria Isaura e que a quarta e a quinta foram prefaciadas por Antonio Candido, sugerimos que Sérgio Buarque construiu relações favoráveis com os e as cientistas sociais da USP. Além disso, Sérgio Buarque auxiliou diretamente Gilda de Mello e Souza em seu doutorado (defendido em 1950), lendo textos em alemão para ela, e participou das bancas de doutorado de Fernando Henrique Cardoso e Octávio Ianni, no começo dos anos de 1960.
} 
caracterizando o ensaio, antes, por suas "inevitáveis contradições" (Leite, 1983, p. 325).

Antonio Candido escreveu duas apresentações a Raízes do Brasil. A primeira saiu na quarta edição do livro, de 1963, na coleção Biblioteca Básica Brasileira, publicada pela Editora da Universidade de Brasília; a segunda foi escrita em 1967 e apareceu pela primeira vez na edição seguinte (a quinta), de 1969, pela José Olympio Editora. Os textos são muito distintos, lembrando que o primeiro foi redigido antes do golpe e, o segundo, depois (Monteiro; Schwarcz, 2016). Apenas no segundo, o crítico reivindica a orientação democrática que Sérgio Buarque teria proposto no livro, interpretação que provavelmente foi motivada pelo contexto do início da ditadura militar, contra a qual Antonio Candido se posicionava. De qualquer modo, como afirmou Leopoldo Waizbort (2011), essa hipótese seria incorporada por gerações sucessivas como guia de leitura quase consensual. Carlos Guilherme Mota (2014), em 1977, foi um dos primeiros a chancelar essa interpretação e autores posteriores, como Pedro Meira Monteiro (1999), Robert Wegner (2000) e Brasílio Sallum Jr. (2012), entre outros, a subscreveram com maior ou menor ênfase.

O texto de Waizbort sacudiu a recepção especializada do livro por meio de uma análise detida de sua primeira edição, de 1936. Notando na segunda edição (1948) a supressão de algumas citações de autores alemães do campo conservador presentes na primeira e mudanças significativas no texto, o autor questionou a interpretação de Antonio Candido, que teria atenuado "as muitas ambiguidades do texto" e firmado "o rumo de uma interpretação mais plana, que diminui suas tensões" (Waizbort, 2011). ${ }^{6}$

\footnotetext{
${ }^{6}$ Esse texto separou as edições de Raízes do Brasil dos anos de 2006 e 2016 e vale notar que a de 2006, por ocasião dos 70 anos da obra foi nomeada "edição comemorativa”, enquanto a de 2016, aos 80 anos, foi uma "edição crítica”. Os termos refletem o impacto do texto de Waizbort na orientação editorial da Companhia das Letras e na recepção recente de Raízes.
} 
Tendo em vista esse debate, o objetivo principal deste artigo é discutir a dimensão política de Raízes do Brasil, a partir de uma reconstrução sucinta da origem familiar e da trajetória de Sérgio Buarque de Holanda, que teriam, possivelmente, condicionado seu posicionamento. De acordo com a interpretação de Robert Wegner, Sérgio Buarque não teria fixado em Raízes do Brasil uma mensagem política unívoca e a forma ensaio que molda o livro permitiria expor as tensões da formação social e política brasileira, testar possibilidades, sem propor uma forma de governo para o país (Wegner, 2009). Sugerimos, assim, que o livro conteria (tanto na primeira, como na segunda edição) um argumento central com desfecho ambíguo, cuja gênese teria relação com a ambivalência da origem social e geográfica de seu autor.

\section{Origem social e trajetória de Sérgio Buarque de Holanda}

A biografia de Sérgio Buarque é conhecida, mas não tanto a genealogia de sua família ${ }^{7}$. Sobre seus ascendentes, as informações mais consistentes e comumente divul-

\footnotetext{
7 A genealogia da família é reconstruída por Bartolomeu Buarque de Holanda, primo de Sérgio Buarque de Holanda, no livro Buarque: uma família brasileira. Ensaio histórico-genealógico (2007), mas o trabalho quase não foi citado por intérpretes de Sérgio Buarque de Holanda. A genealogia aqui resumida apoia-se nessa obra e na dissertação de mestrado Duas raízes: o ensaísmo de Sérgio Buarque de Holanda, de Monica Isabel de Moraes (2017), que interpreta as informações ali contidas à luz de sua perspectiva de análise. Vale a pena citar uma passagem na qual Bartolomeu Buarque de Holanda narra a origem de seu trabalho, que teria se dado em diálogo direto com Sérgio Buarque e seus irmãos: "O trabalho ora apresentado constitui um primeiro volume e é o resultado de uma longa pesquisa, coletando informações desde meados da década de 1970, ouvindo as histórias de família, dos parentes mais antigos, inicialmente nos estados de Alagoas e Pernambuco. [...] Numa visita a São Paulo, em casa do historiador Sérgio Buarque de Holanda, em abril de 1978, comecei as primeiras indagações. No Rio de Janeiro, as longas conversas e a convivência enriquecedora com Cecília, Jayme e Aurélio Buarque de Hollanda motivaram-me a dar início à pesquisa. Essas conversas animadas, despertaram-me o interesse e a curiosidade de conhecer um pouco da vida cotidiana de nossos antepassados. Em 1980, retornando ao Nordeste, iniciei as primeiras pesquisas em fontes primárias, tais como livros de batismo, casamento e óbito [...] arquivos de diversos cartórios, igrejas, cemitérios, bibliotecas, universidades e instituições de pesquisa, tanto no Brasil como no exterior" (Holanda, 2007, pp. 17-18).
} 
gadas referem-se apenas a seu pai. Christovam Buarque de Holanda nasceu em 1861, na cidade de Rio Formoso/PE. Sobre sua mãe, Heloisa Costa Buarque de Holanda, pouco se sabe. Ela nasceu em Niterói/RJ no ano de 1868 e foi criada pelos padrinhos na capital paulista. Eles se casaram no ano de 1901 em São Paulo.

No prólogo ao volume inaugural da coleção Documentos Brasileiros, da José Olympio, Gilberto Freyre, seu primeiro organizador, apresentou Sérgio Buarque de Holanda, como um "escritor paulista”, mas é provável que ele soubesse, sendo de Pernambuco, que a antiga família de Sérgio pertencia às oligarquias do açúcar desse estado e de Alagoas. Seus avós por parte de pai, Manuel Buarque de Gusmão Lima e Maria Magdalena Paes de Holanda Cavalcanti, pertenciam a famílias de grandes proprietários. Manuel nasceu em 1823, Maria Magdalena, em 1835, nos engenhos de suas famílias.

330 A narrativa da festa de quinze anos de Maria Magdalena por Bartolomeu Buarque de Holanda, é reveladora da posição social e do estilo de vida de sua família, que Christovam, diretamente, e Sérgio, indiretamente, herdaram em boa medida.

O aniversário de 15 anos de Maria Magdalena foi comemorado em 1850, com todo o requinte, no Engenho Pandorra, de propriedade de sua tia-avó Maria Rita Albuquerque de Melo, irmã de seu avô Christovam de Hollanda Cavalcanti e mãe do Visconde de Albuquerque, Francisco de Paulo de Hollanda Cavalcanti. A casa-grande do Marrecas, um suntuoso casarão de posição privilegiada, erguido majestoso e imponente sob uma colina onde da varanda ou das janelas se avista um enorme jardim florido, é lembrada como o local em que eram realizados os grandes acontecimentos, as grandes festividades, e onde se reunia toda a família Hollanda Cavalcanti, assim como os amigos e 
primos que vinham de outros engenhos nos finais de tarde, quando se liam os clássicos franceses, no enorme salão, claro e arejado, com muitas janelas e uma grande mesa de jantar com 18 lugares, sempre farta e movimentada, com variadas iguarias, bolo, perus, porco assado, bode, peixes, doces caseiros, licores e compotas diversas, candelabros e talheres de prata e louça inglesa. Diversos objetos de arte adornavam o ambiente. Também havia os saraus, organizados por sua avó Paula e sua tia Maria Rita Albuquerque de Melo, nos quais Maria Magdalena, tios e primos demonstravam seus conhecimentos artísticos adquiridos com os professores estrangeiros. Havia uma grande varanda ao redor, cercada por um gramado muito verde. Eram tardes muito alegres e agradáveis, frequentadas pelas senhoras de outros engenhos (Holanda, 2007, p. 133).

O casamento entre Manuel Buarque de Gusmão Lima e Maria Magdalena Paes de Holanda Cavalcanti ocorreu no Engenho Marrecas, em Maragogi/AL, em 1850. A vida do casal e da família alternaria, entretanto, um período inicial de relativa estabilidade econômica, em função da renda proveniente dos engenhos que administravam, a outro de declínio, acentuado na década de 1880, no compasso da crise do império e do escravismo, culminando com uma situação de insolvência posterior. $\mathrm{O}$ casal teve oito filhos e Christovam Buarque de Holanda Cavalcanti, o pai de Sérgio Buarque, foi o terceiro. Sua origem social e trajetória seriam muito próximas às que Gilberto Freyre descreveu em Sobrados $e$ Mucambos (1936) como típicas para os diplomados brasileiros na segunda metade do século XIX. Oriundo, como vimos, de uma família da oligarquia nordestina em franco declínio, buscaria no ensino superior a recuperação possível da posição social de seus antepassados (Miceli, 2012).

Christovam foi educado no engenho de sua família por professores particulares e enviado à escola em Maceió aos 
onze anos de idade. Ele ainda estudaria em Recife antes de migrar para o Rio de Janeiro para cursar medicina. Essa escolha foi estimulada pelo fato de um tio materno, professor de matemática da Escola Politécnica, residir no Rio de Janeiro. Christovam aportou na então capital federal em 1885 e logo soube que seu tio havia falecido poucos dias antes de sua chegada. Diante de tal circunstância, iniciou o curso de medicina suportado por seu pai, mas não logrou concluí-lo. No final da década de 1880, em função de dificuldades financeiras já mencionadas, seu pai interromperia o envio do dinheiro necessário à sua manutenção na então capital do país.

Só permaneceu no Rio de Janeiro porque foi aprovado no concurso público para o posto de químico no Laboratório da Alfândega do Rio de Janeiro. A transferência para o curso de Farmácia, que concluiria, permitiu conciliar trabalho e estudo e, anos mais tarde, assumir em São Paulo o cargo de 332 diretor do Laboratório de Análises do Estado de São Paulo. Ele seria, ainda, chefe do Serviço Sanitário desse estado e um dos fundadores da Escola de Farmácia, Odontologia e Obstetrícia, posteriormente incorporada à Universidade de São Paulo. Por meio desse itinerário concretizaria a recuperação econômica e social almejada, distanciando-se progressivamente do estilo de vida da oligarquia do açúcar.

Casou-se com Heloisa Costa Buarque de Holanda aos 40 anos de idade (ela estava com 34) e se estabeleceu em São Paulo, primeiro no bairro da Liberdade, depois em Higienópolis. Tal desfecho da reconversão social de Christovam $^{8}$ justifica a caracterização da origem social de Sérgio Buarque, por Francisco Iglesias (2009), de forma explícita, e por Francisco de Assis Barbosa, implicitamente, como de "classe média":

\footnotetext{
8 O casamento tardio pode sinalizar que Christovam teria resolvido sua vida sentimental após sua estabilização profissional, estratégia relativamente comum para jovens egressos de famílias que experimentaram forte declínio econômico e social.
} 
Seu pai era funcionário público, digamos alto funcionário; ao fim da carreira burocrática, aposentou-se como diretor do Almoxarifado do Serviço Sanitário do Estado. Lecionou Botânica na Escola de Farmácia e Odontologia, de que fora um dos fundadores. Seus vencimentos asseguravam-lhe, sem dúvida, uma vida decente, instalado em bairro burguês, boa casa, onde abrigava a família, mulher e três filhos, para alimentar, vestir e educar. Todos frequentaram os melhores colégios da época, da Escola Modelo Caetano de Campo ao Colégio São Bento [...] (Barbosa, 1988, p. 30, destaque nosso).

Figura 1

Foto de Família. São Paulo, 1916

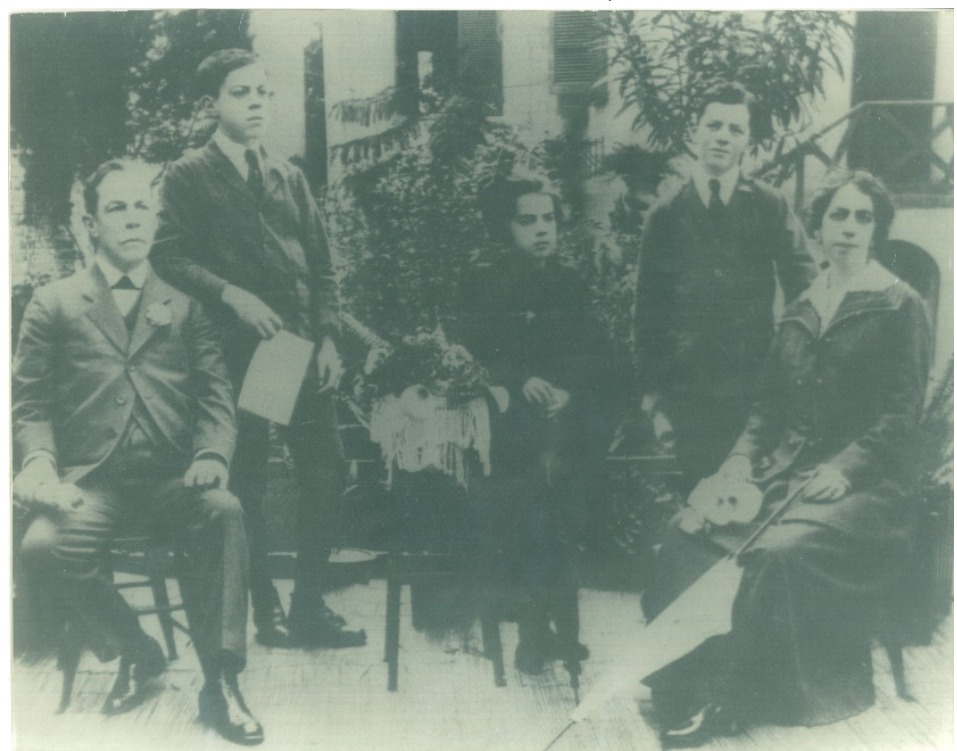

Sérgio Buarque de Holanda, nos jardins de sua residência à Rua Piauí, em São Paulo, com seus pais e irmãos, 1916.

Fonte: Fundo Sérgio Buarque de Holanda, mantido pelo Arquivo Central do Sistema de Arquivos (Área de Arquivo Permanente) da Universidade Estadual de Campinas - Siarq/Unicamp [Vp 3 P1]. 
O casal teria três filhos, Sérgio (1902-1982), Jayme (1904-1997) e Cecília (1908-1999), ${ }^{9}$ todos educados em boas escolas. Sérgio iniciou sua escolarização cedo para os padrões da época, no Jardim da Infância do Colégio Progresso Brasileiro, depois passou à Escola Modelo Caetano de Campos, onde fez o primário, e ao Colégio São Bento, no qual cursou a maior parte do ginásio, voltado à elite paulistana, de acordo com textos de celebração da história dessa instituição escolar:

As aulas na nova instituição de ensino em São Paulo tiveram início a 15 de fevereiro de 1903. O primeiro aluno matriculado foi Gofredo da Silva Teles de família distinta (e que se tornou prefeito de São Paulo em 1932). Dentre os docentes na ocasião da fundação estavam grandes nomes da sociedade paulistana. Podemos citar alguns como Batista Pereira, Tobias de Aguiar, Miguel Ferreira, Alfredo Pacheco Ademar de Melo Franco, Albert Levy e o historiador Affonso d'Escragnolle Taunay. (Barbosa, 2013)

O percurso indica a aposta de seus pais na acumulação de capital cultural dos filhos como estratégia de confirmação da recuperação social anteriormente alcançada por eles. Esse itinerário, e especialmente o Colégio São Bento, imprimiria marcas duradouras no então jovem estudante. Isso se daria em dois aspectos principais, se considerada a escritura de Raízes do Brasil. O primeiro foi a aprendizagem do alemão, que lhe facultaria depois a ida à Alemanha como

9 Jayme Buarque de Holanda (7/2/1904, São Paulo, SP; 26/8/1997, Rio de Janeiro/RJ), foi empresário, tendo atuado na área de peças automotivas. Casou-se em 22/11/1938 com Maria Carlota Machado da Silva (Holanda, 2007, p. 217). Cecília Buarque de Holanda (10/10/1908, São Paulo, SP; 4/8/1999, Rio de Janeiro, RJ), foi estatística, funcionária pública, tendo ingressado por concurso no Ministério da Agricultura, em 1934. A partir de 1968, transfere-se para o IBDF Instituto Brasileiro de Desenvolvimento Florestal, onde se aposenta em 1974, após completar quarenta anos de serviço público. Dedicou-se ao serviço social como membro do Colégio Sion (Holanda, 2007, p. 221). Ela não se casou. 
correspondente de O jornal, em 1929, e a leitura das inúmeras fontes teóricas, especialmente Max Weber, referência central para a construção do livro; o segundo foi ter sido aluno de Afonso Taunay, um dos principais historiadores das bandeiras, que lhe infundiu o gosto pela história e pelo problema específico da expansão paulista, como assumiu em entrevista:

Minha matéria favorita era história, ensinada lá por Afonso d'Escragnolle Taunay. Li cronistas portugueses do século XV, como Fernão Lopes. Saltei páginas por vezes, mas copiei capítulos inteiros num caderno escolar que ainda tenho. (Graham, 1982, p. 1175)

Além disso, Taunay intermediou a publicação de Originalidade literária, o primeiro artigo de Sérgio Buarque, no Correio Paulistano, jornal diretamente ligado ao PRP, no qual passou a colaborar. A experiência seria decisiva para sua aproximação ao grupo modernista:

Com a ajuda de Taunay, publiquei meu primeiro artigo no Correio Paulistano, quando tinha dezoito anos. Comecei então a escrever com frequência em suas colunas literárias e conheci muitos dos líderes do nascente Movimento Modernista, como Mário de Andrade, Oswald de Andrade, Sérgio Milliet, Menotti del Picchia e Rubens Borba de Moraes. Naquele tempo, encontrei também Monteiro Lobato e Yan de Almeida Prado. (Graham, 1982, p. 1175)

Pouco depois, em 1921, ocorreria a mudança de seus pais ao Rio de Janeiro, que Sérgio acompanhou. Na Capital Federal cursou a Faculdade de Direito, "embora não sentisse nenhuma vocação para os estudos jurídicos, nem pensasse em seguir a carreira de advogado" (Barbosa, 1988, p. 33). De fato, não exerceu a profissão, tendo se sustentado na 
década de 1920 com colaborações variadas à imprensa. Nesses meios, ingressou num círculo de sociabilidade cultural e política intensa, iniciado pelas amizades travadas com Prudente de Moraes Neto e Afonso Arinos de Mello Franco. Sua chegada ao Rio de Janeiro ficaria marcada por sua atuação como representante do modernismo paulista, não apenas por meio da revista Klaxon, mas também por intermediar contatos entre os grupos paulista e carioca (Wegner, 2009). A curta existência da revista Estética, fundada com Prudente de Moraes Neto em 1924, reforçou tais vínculos e o projetou nos círculos culturais cariocas. Os gêneros aos quais se dedicou nas décadas de 1920 e 1930, sobretudo a crítica literária, derivaram desse contexto.

A viagem à Alemanha, em junho de 1929, como correspondente dos jornais de Assis Chateaubriand, seria decisiva para sua trajetória intelectual posterior, em função da familiarização com a sociologia e a filosofia produzidas nesse país no contexto político de grande polarização entre a unificação (1870) e a ascensão do nacional-socialismo (1933), passando pela Primeira Guerra (1914-1918) e a República de Weimar (1919-1933). Sobretudo Max Weber, mas também autores ligados à filosofia vitalista conservadora seriam incorporados por Sérgio Buarque em Raízes do Brasil (Waizbort, 2011). Após o retorno ao seu país, em janeiro de 1931, continuou a trabalhar como jornalista na primeira metade dessa década, quando apoiou o Movimento Constitucionalista de 1932 (Holanda, 2006), até ingressar, em 1936, na Faculdade de Filosofia e Letras da Universidade do Distrito Federal (UFD), como assistente do professor francês Henri Hauser (1866-1946) na cadeira de história moderna e econômica, que influenciou passos posteriores de Sérgio Buarque como historiador a partir de Monções (1945), por intermediação de seu grande amigo Prudente de Moraes Neto, então diretor da instituição. Pouco antes, havia publicado em 1935, na revista Espelho, o artigo "Corpo e alma 
do Brasil: ensaio de psicologia social”, que obteve acolhida favorável no meio intelectual carioca, influenciando possivelmente a decisão de Gilberto Freyre e José Olympio de iniciar a Coleção Documentos Brasileiros com a publicação de Raizes do Brasil, em 1936.

Esse ano foi decisivo para Sérgio Buarque, também, em função do casamento com Maria Amélia Cesário Alvim, nascida em 1910 no Rio de Janeiro. Ela era neta de José Cesário de Faria Alvim, quem havia sido governador de Minas Gerais, além de senador e ministro do interior durante a presidência de Deodoro da Fonseca. O pai de Maria Amélia, Francisco Cesário Alvim, foi desembargador. Esses dados indicam o pertencimento da esposa à uma família poderosa da oligarquia mineira e a importância possível do casamento para reforçar a recuperação social de Sérgio Buarque ${ }^{10}$ e de sua família de origem. O casal teria quatro filhas e três filhos, conformando do ponto de vista morfológico uma estrutura familiar tradicional, pela coesão, força das figuras paterna (dominante) e materna, além de descendência numerosa. Nesse sentido, o filme de Nelson Pereira dos Santos Raizes do Brasil: uma cinebiografia de Sérgio Buarque de Holanda (2003) oferece um retrato sugestivo da família. No filme, Antonio Candido relata em depoimento a colaboração de Maria Amélia, que foi pianista amadora (Citelli, 2010), com o marido, não só pelo cuidado da casa e dos filhos, mas, também, pelo suporte ao trabalho intelectual. Deve-se notar, ainda, que o casamento e a publicação de Raízes do Brasil demarcam a transição entre o intelectual polígrafo (jornalista, ensaísta e crítico literário) que prevaleceu até então e o intelectual acadêmico (historiador) que se constituiria a partir daí, embora não de modo linear e imediato.

\footnotetext{
${ }^{10}$ Vale a pena reproduzir trecho de depoimento de Sérgio Buarque que avalia a importância de seu casamento: "Você pode dizer que sosseguei: casei-me em 1936 e mudei para uma casa na Praia do Leme, com uma varanda nos dois andares, que davam para o mar" (Graham, 1982, p. 1177)
} 

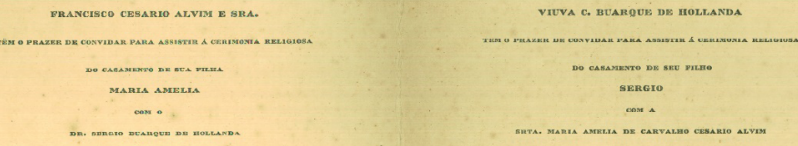

Du an

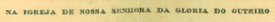

Fonte: Fundo Sérgio Buarque de Holanda, mantido pelo Arquivo Central do Sistema de Arquivos (Área de Arquivo Permanente) da Universidade Estadual de Campinas - Siarq/Unicamp [Documentos Complementares CX 03, item 24].

Apesar do fechamento da UDF em 1939, interrompendo a carreira docente nesse momento, Sérgio Buarque seria incorporado ao Instituto Nacional do Livro (INL), convidado por seu então diretor Augusto Meyer, e desse modo, ao quadro de intelectuais direta ou indiretamente envolvidos na sustentação do Estado Novo (Miceli, 1979). Além da chefia da Seção de Publicações no INL (posto que deixaria em 1944 para assumir a direção da Divisão de Consulta da Biblioteca Nacional até 1946), iniciou ainda a colaboração regular como crítico literário do Diário de Notícias em 1940. Publicou sua coluna até o início de 1941, retomando-a entre 1947 e 1950 (Serrano, 2016).

A etapa carioca da trajetória de Sérgio Buarque pode ser compreendida, da mesma forma que a migração de muitos escritores contemporâneos provindos de outros estados, como um requisito essencial para sua legitimação intelectual nacional, o que só o Rio de Janeiro poderia conferir, especialmente, entre as décadas de 1920 e 1940. Talvez apenas os paulistas pudessem escapar desse itinerário, como se deu com a maioria dos modernistas, que apenas raramente ou por períodos curtos fixaram residência na então Capital Federal. Nesse sentido, Sérgio Buarque foi uma exceção, mas devemos lembrar que seu vínculo com São Paulo não poderia ser o mesmo que 
o de intelectuais e artistas paulistas herdeiros das famílias tradicionais ligadas à economia do café (Tarsila do Amaral, Paulo Prado, Caio Prado Jr. e outros) ou da burguesia industrial que despontava (Oswald de Andrade). De qualquer forma, independentemente dos motivos que levaram seu pai e sua mãe de volta ao Rio de Janeiro, e com eles Sérgio e seus irmãos Jayme e Cecília, no começo dos anos de 1920, a longa permanência na cidade foi decisiva para a construção inicial de sua carreira profissional, para o estabelecimento do cabedal de relações sociais que a estribaram, e para a formatação de sua identidade de intelectual "brasileiro", aparentemente distanciado da ambivalência de sua origem familiar, e comprometido com as questões ligadas à formação e modernização do país, afloradas no curso do varguismo.

Voltaria, finalmente, a São Paulo (1946), para assumir a direção do Museu Paulista, em substituição a seu antigo professor no Colégio São Bento Afonso E. Taunay. A relação com Taunay foi importantíssima, como vimos, e se deu em vários planos. A provável indicação de Sérgio Buarque por Taunay para assumir a direção do museu teria sido um deles. Além disso, haveria a transmissão do interesse pela história de São Paulo, especialmente, pelo tema das entradas e bandeiras. Taunay escreveu vários livros sobre tais temas, entre os quais a História geral das bandeiras paulistas (1936). Significativamente, a publicação de Monções (1945) ocorreu um ano antes do retorno a São Paulo, inaugurando na produção do historiador que se anunciava o interesse mais explícito pela história paulista, por suas singularidades, a colonização do interior e orientação modernizadora no contexto nacional. Vale notar que a segunda edição de Raízes do Brasil, que saiu "consideravelmente modificado na presente versão" (Holanda, 2016, p. 347), foi publicada em 1948, portanto, após o retorno a São Paulo.

Um interesse incipiente pela história de São Paulo, entretanto, já se pode reconhecer em passagens de Raízes do Brasil, 
desde sua primeira edição. No capítulo 4 "O passado agrário (continuação)", renomeado na edição seguinte como "O semeador e o ladrilhador", o autor valoriza a "obra grandiosa"11 das bandeiras paulistas, atribuindo a São Paulo um papel de protagonista na luta pela autonomia da colônia:

No planalto de Piratininga nasce em verdade um momento novo de nossa história nacional. Ali, pela primeira vez, a inércia difusa da população colonial adquire forma própria e encontra uma voz articulada. (Holanda, 2016, p. 176)

Ainda nesse capítulo, uma das quatro notas introduzidas na segunda edição, "A língua geral em São Paulo", sugere que o interesse pela história paulista e por seu significado para o Brasil se ampliou na segunda edição. Enfatizamos, também que essa nota introduz no livro uma dicção historiográfica, que já se pode perceber em Monções e mais ainda 340 nos trabalhos posteriores. Embora a nota trate da questão específica da língua falada na região durante a colonização, há um tom enaltecedor a respeito dessa experiência singular no interior da história nacional. Enfatizamos, ainda, a menção afetuosa a seu antigo professor ao agradecer a cessão de um "documento manuscrito que me acaba de ser amavelmente comunicado pelo mestre Afonso de Taunay" (Holanda, 2016, p. 220).

Adiante no livro, no último capítulo, "Nossa Revolução", uma parte significativa (cerca de duas páginas na primeira edição e de quatro na segunda), reitera o papel modernizador de São Paulo a partir de outra conjuntura histórica, agora referindo-se ao processo de substituição do açúcar pelo café como produto de exportação principal do país. Na primeira edição, esse movimento está subentendido, uma vez que não há menção direta à São Paulo ou ao Oeste

${ }_{11}$ Adjetivo suprimido na segunda edição. 
Paulista. Na segunda edição, a menção à São Paulo é explícita. Segundo o autor, o padrão anterior da fazenda que buscava ser autossuficiente, como teriam sido a produção do açúcar no Nordeste e do café no Vale do Paraíba, seria superado por um novo tipo de exploração, mais afinado com a economia capitalista e com a urbanização:

É particularmente no Oeste da província de São Paulo o Oeste de 1840 e não o de 1940 - que os cafezais adquirem seu caráter próprio, emancipando-se das formas de exploração agrária estereotipadas desde os tempos coloniais no modelo clássico de lavoura canavieira e do 'engenho' de açúcar. A silhueta antiga do senhor de engenho perde aqui alguns dos traços característicos, desprendendo-se mais da terra e da tradição - da rotina - rural. A terra de lavoura deixa então de ser o seu pequeno mundo para se tornar unicamente seu meio de vida, sua fonte de renda e de riqueza. A fazenda resiste com menos energia à influência urbana, e muitos lavradores passam a residir permanentemente nas cidades. Decai rapidamente a indústria caseira e diminuem em muitos lugares as plantações de mantimentos, que garantiam outrora certa autonomia à propriedade rural" (Holanda, 2016, p. 306)

As alterações realizadas na segunda edição (1948) reforçaram, assim, uma linha argumentativa, que atribui indiretamente ao estado de São Paulo o papel de condutor principal da modernização brasileira, de acordo com o lema principal da elite paulistana, estampado no brasão da cidade, non ducor duco (não sou conduzido, conduzo). Embora já identificável na primeira edição (1936), a ênfase nesse argumento deve ser remarcada, uma vez que estava em sintonia com o retorno de Sérgio Buarque a São Paulo, onde viria a se inserir profissionalmente, primeiro como diretor no Museu Paulista (1946-1956), quase ao mesmo tempo como 
professor na Escola Livre de Sociologia e Política (19471955) e, depois, na Universidade de São Paulo, onde ingressou em 1956 como professor contratado para a cadeira de História da Civilização Brasileira, sendo aprovado em concurso para professor catedrático em 1958, sucedendo o primeiro titular Afonso D'Escragnole Taunay e o segundo Alfredo Ellis Júnior (Rodrigues, 2011, p. 283) e assim conformando uma linhagem de historiadores de São Paulo. Ele se aposentaria em 1969, em apoio aos colegas afastados compulsoriamente pela ditadura militar (Holanda, 2006).

\section{Geografia e política}

O peso da origem geográfica (estadual e regional) na vida intelectual brasileira, sobretudo, a partir da República, é uma dimensão importante a ser considerada. ${ }^{12}$ Não por acaso, três dos principais ensaístas dos anos de 1920, os chamados pensadores autoritários, nasceram no estado do

342 Rio de Janeiro. A reivindicação de um Estado nacional forte e centralizado por autores como Oliveira Vianna, Azevedo Amaral e Alberto Torres, apesar das diferenças entre as interpretações que propuseram, envolvia uma disputa com São Paulo, que havia assumido a dianteira da política nacional e deslocado o Rio de Janeiro dessa posição na Primeira República. Após a Revolução de 1930, com a derrota paulista (ratificada em 1932), o ensaísmo ganhou força em São Paulo, por meio de Caio Prado Jr. e Sérgio Buarque de Holanda. O outro grande ensaísta do período, Gilberto

\footnotetext{
12 Comparando-se a outros países da América Latina, como México e Argentina (além de casos europeus como o da França), cujos sistemas culturais se constituíram de modo centralizado (Buenos Aires, Cidade do México e Paris), a experiência brasileira aproxima-se de outras (como a da Alemanha, dos Estados Unidos e da Rússia) caracterizadas pela descentralização ou, dito de outro modo, pela configuração multipolar. No caso brasileiro, isso se relaciona com as sucessivas temporalidades econômicas e políticas que implicaram desde a colonização a ascensão e declínio de centros como Salvador, Recife, Ouro Preto e outros. Desde o começo do século XX, como se sabe, as cidades do Rio de Janeiro e São Paulo disputaram a dianteira cultural e científica do país.
} 
Freyre, era pernambucano e havia sido deposto em 1930 com o governador Estácio Coimbra, de quem era secretário (Bastos, 1999). Embora diferentemente, Casa-grande Ev senzala (1933), Raízes do Brasil (1936) e Formação do Brasil contemporâneo (1942) relacionam-se com a geografia política e intelectual inaugurada pelo varguismo, do qual os três estavam alijados e em oposição.

Lembramos que, apesar de nascido e educado em São Paulo, a origem familiar de Sérgio Buarque remonta às oligarquias do açúcar de Pernambuco e Alagoas. Tal ambivalência pode ser notada na argumentação construída no livro. Assim, se em Raízes do Brasil o autor respondeu ao contexto político do início da década de 1930, especificamente aos primeiros anos do governo de Getúlio Vargas, como sugerem vários intérpretes (Waizbort, 2011; Sallum, 2012; Bastos, 2016), a favor de São Paulo, defendendo que o processo de lenta transformação do país, que teve a abolição como marco principal a partir da segunda metade do século XIX, contou com os paulistas como protagonistas; também reivindicou a tradição do Nordeste (reforçando uma das bases da argumentação de Gilberto Freyre em Casa Grande Ẽ Senzala), por meio da reconstrução histórica da sociedade patriarcal brasileira, e de algum modo, a herança ibérica, o personalismo e a ética da aventura.

A avaliação do "personalismo", a estrutura de personalidade herdada do colonizador português e ajustada às condições da colonização, como um fator positivo ou negativo, seria a chave para a compreensão do livro. ${ }^{13}$ De qualquer modo, se há hoje um consenso entre os intérpretes sobre

\footnotetext{
13 Esquematicamente, haveria três leituras possíveis para a interpretação sugerida por Sergio Buarque sobre o personalismo como disposição psicossocial envolvida em nossa formação histórica. O personalismo poderia ser sempre favorável, tanto no Brasil colônia como no Brasil nação; favorável na colônia e desfavorável na nação ou desfavorável nos dois períodos. Devemos sublinhar que a escolha entre essas alternativas depende da leitura que fazemos do livro, uma vez que o texto redigido por seu autor não é assertivo sobre esse ponto.
} 
um argumento central de Raízes do Brasil, ele se refere ao descompasso diagnosticado por Sérgio Buarque entre o personalismo e a democracia. As diferenças de interpretação teriam a ver, então, com as leituras sobre as possíveis soluções preconizadas pelo autor para as alternativas de superação desse impasse. Em outros termos, a ambiguidade diz respeito, sobretudo, ao caminho político a ser então adotado.

A interpretação estabelecida por Antonio Candido no texto "O significado de Raízes do Brasil”, referendada por inúmeros especialistas, supõe que a mensagem política de Sérgio Buarque seria progressista e democrática e que, nesse sentido, o personalismo seria um entrave a ser ultrapassado pelo avanço da democracia, sustentada pela urbanização, desenvolvimento econômico associado à economia do café, abolição da escravidão e emergência econômica e política do trabalhador livre:

[...] Trata-se de liquidar o passado, adotar o ritmo urbano e propiciar a emergência das camadas oprimidas da população, únicas com capacidade para revitalizar a sociedade e dar um novo sentido à vida política. (Candido, 2016, p. 367)

Um dos méritos principais do texto "O mal-entendido da democracia, Raízes do Brasil, 1936”, de Leopoldo Waizbort, foi descolar essa apresentação, tornada guia de leitura obrigatório, do livro de Sérgio Buarque, de modo que a interpretação de Antonio Candido desde então passou a ser questionada e não mais aceita como definitiva e verdadeira a priori. A argumentação de Waizbort baseou-se no cotejo das duas primeiras edições do livro e na constatação de que seu autor teria realizado mudanças, excluindo trechos e referências e incluindo, além de notas longas ao capítulo 4, novas passagens e formulações que teriam alterado o sentido da primeira edição, principalmente, em relação à direção política que ela supostamente defendia. Ainda baseado na primeira edição, Waizbort argumenta que Sérgio Buarque consideraria o personalismo 
como essencial ao caráter (atemporal) da nação, reivindicando-o como fundamento a ser retido da ordem política em construção no país, avessa à democracia e afinada, num espírito antiliberal, à oligarquia como forma de governo.

Acerca dessas duas interpretações, a de Antonio Candido baseada provavelmente na edição que seria publicada em 1969 e a de Leopoldo Waizbort na primeira edição de 1936, entendemos que ambas são defensáveis, sobretudo, para as edições diferentes que tiveram como referência. De fato, algumas supressões e acréscimos realizados da primeira para a segunda edição atenuaram um viés que pode ser interpretado como conservador e reforçaram sua possível orientação progressista, como as passagens seguintes confrontadas, citadas por Waizbort (2011, p. 52), sugerem:

Entre nós, já o dissemos, o personalismo é uma noção positiva - talvez a única verdadeiramente positiva que conhecemos. Ao seu lado todos os lemas da democracia liberal são conceitos puramente decorativos, sem raízes profundas na realidade. Isso explica bem como nos países latino-americanos, onde o personalismo - ou mesmo a oligarquia, que é o prolongamento do personalismo no espaço e no tempo - conseguiu abolir as resistências da demagogia liberal, acordando os instintos e os sentimentos mais vivos do povo, tenha assegurado, com isso, uma estabilidade política que de outro modo não teria sido possível. A formação de elites de governantes em torno de personalidades prestigiosas tem sido, ao menos por enquanto, o princípio político mais fecundo em nossa América. (Holanda, 1936, 1ª edição, p. 152)

É inegável que em nossa vida política o personalismo pode ser em muitos casos uma força positiva e que ao seu lado os lemas da democracia liberal parecem conceitos puramente ornamentais ou declamatórios, sem raízes fundas na realidade. 
Isso explica como, entre nós e, em geral, nos países latino-americanos, onde quer que o personalismo - ou a oligarquia, que é o prolongamento do personalismo no espaço e no tempo - conseguiu abolir as resistências liberais, assegurou-se, por essa forma, uma estabilidade política aparente, mas que de outro modo não seria possível. (Holanda, 1948, 2ª edição, pp.275-276)

Além de alterações como essas, alguns acréscimos na segunda edição justificam uma leitura que confere ao livro uma perspectiva progressista, como é o caso das passagens inseridas após o parágrafo em que Sérgio Buarque discute a necessidade de se ultrapassar a antítese "liberalismo-caudilhismo" (esse parágrafo começa com a palavra "Colocado" e termina com "liberalismo-caudilhismo"), especialmente a subsequente, que foi introduzida na segunda edição:

Essa vitória nunca se consumará enquanto não se liquidem, por sua vez, os fundamentos personalistas e, por menos que o pareçam, aristocráticos, onde ainda assenta nossa vida social. Se o processo revolucionário a que vamos assistindo, e cujas etapas mais importantes foram sugeridas nestas páginas, tem um significado claro, será este o da dissolução lenta, posto que irrevogável, das sobrevivências arcaicas, que o nosso estatuto de país independente até hoje não conseguiu extirpar. Em palavras mais precisas, somente através de um processo semelhante teremos finalmente revogada a velha ordem colonial e patriarcal, com todas as consequências morais, sociais e políticas que ela acarretou e continua a acarretar (Holanda, 2016, p. 317-318)

\section{Conclusão}

De acordo com Brasílio Sallum Jr. (2012) e Élide Rugai Bastos (2016), as mudanças realizadas por Sérgio Buarque 
precisam ser compreendidas, também, a partir das transformações históricas de grande impacto ocorridas entre a publicação da primeira e da segunda edição, tanto no plano nacional quanto mundial. A primeira é anterior ao início do Estado Novo (1937) e da Segunda Guerra (1939), enquanto a segunda é posterior ao fim da guerra (1945) e do Estado Novo (1945). Certamente, o ensaísta adequou o livro ao contexto do pós-guerra e da democratização. Relembramos, ainda, que entre as edições houve reorientação da trajetória profissional do autor, que retornou do Rio de Janeiro a São Paulo para dirigir o Museu Paulista.

De qualquer forma, entendemos que, apesar de todas as alterações e suas possíveis motivações, o livro se manteve essencialmente o mesmo nas duas edições, porque o diagnóstico sobre o impasse político do país não foi alterado (descompasso entre personalismo e democracia), tampouco a indefinição ou ambiguidade a respeito do projeto político a ser adotado. Ou seja, do nosso ponto de vista o autor não foi, em nenhuma das duas edições, assertivo em seu posicionamento político, como afirmado por Robert Wegner (2009). ${ }^{14}$

O argumento de Raízes do Brasil conteria, assim, um desfecho ambíguo. ${ }^{15}$ Lembremos, nessa direção, o parágrafo decisivo e pouco alterado do penúltimo capítulo do

\footnotetext{
14 Nas palavras do autor: "De todo modo Raízes do Brasil é fundamentalmente um ensaio que testa possibilidades e expõe tensões do nosso processo de modernização." (Wegner, 2009, p. 218)

15 Vale citar uma passagem do texto "Um ensaio entre o passado e o futuro", no qual Robert Wegner interpreta o movimento pendular do argumento de Sérgio Buarque em Raizes do Brasil: "Em primeiro lugar, Sérgio Buarque construiu uma narrativa na qual alterna a descrição de eventos particulares com generalizações interpretativas, numa operação que considero semelhante a um constante abrir e fechar dos olhos; em segundo lugar, o autor analisa suas generalizações a partir de diferentes perspectivas, ora lhes atribuindo sinal positivo, ora negativo, lembrando uma variação no ângulo de visão; e por último, comparando o que seria um olhar para trás alternado com um olhar adiante, o livro chama a atenção para a mudança avassaladora na sociedade brasileira e, ao mesmo tempo, recupera elementos da tradição”. (Wegner, 2006, p. 337)
} 
livro, "Novos tempos", no qual consta a famosa frase sobre a democracia no Brasil:

Mas os positivistas foram apenas os exemplares mais característicos de uma raça humana que prosperou consideravelmente em nosso país, logo que este começou a ter consciência de si. De todas as formas de evasão da realidade, a crença mágica no poder das ideias pareceu-nos a mais dignificante em nossa difícil adolescência política e social. Trouxemos de terras estranhas um sistema complexo e acabado de preceitos, sem saber até que ponto se ajustam às condições da vida brasileira e sem cogitar das mudanças que tais condições lhe imporiam. Na verdade, a ideologia impessoal do liberalismo democrático jamais se naturalizou entre nós. Só assimilamos efetivamente esses princípios até onde coincidiram com a negação pura e simples de uma autoridade incômoda, confirmando nosso instintivo horror às hierarquias e permitindo tratar com familiaridade os governantes. A democracia no Brasil foi sempre um lamentável malentendido. Uma aristocracia rural e semifeudal importou-a e tratou de acomodá-la onde fosse possível aos seus direitos e privilégios, os mesmos privilégios que tinham sido, no velho mundo, o alvo da luta da burguesia contra os aristocratas. E assim puderam incorporar à situação tradicional, ao menos como fachada ou decoração externa, alguns lemas que pareciam os mais acertados para a época e eram exaltados nos livros e discursos. (Holanda, 2016, p. 280-281, destaque nosso)

Se Sérgio Buarque expressa de forma contundente sua crítica ao modo de implantação da democracia no Brasil, descompassado entre o arcabouço legal (democracia/liberalismo) e a realidade (patriarcalismo/personalismo) - problema típico de um país subjugado que tentava se transformar por meio da importação irrefletida de modelos legais e políticos estrangeiros -, não explicita o caminho que deveria 
ser seguido. Sugerimos que essa ambiguidade do desfecho de seu argumento, indefinido quanto à sua proposta política, sedimenta a ambivalência da origem social e geográfica de seu autor, entre oligarquia e burguesia, entre Nordeste e Sudeste e, portanto, entre dois modos distintos de refletir sobre nossa formação histórica e social e as possibilidades de transformação, plasmados em tensão no livro.

Finalizamos este artigo, então, com a citação da passagem célebre da abertura de Raízes do Brasil (Holanda, 2016, p. 39), que pode ser lida como o núcleo da experiência familiar ambivalente de Sérgio Buarque que, segundo nossa interpretação, estaria na gênese da ambiguidade de seu argumento: "somos ainda hoje uns desterrados em nossa terra".

\section{Monica Isabel De Moraes}

Graduada em Direito pela Universidade de São Paulo (USP) e em Ciências Sociais pela Faculdade de Filosofia, Letras e Ciências Humanas (FFLCH) da USP. Mestre em Sociologia e Doutoranda em Sociologia pela FFLCH - USP.

\section{Luiz Carlos Jackson}

Sociólogo e professor do Departamento de Sociologia, na Faculdade de Filosofia, Letras e Ciências Humanas (FFLCH) da Universidade de São Paulo (USP). Um dos coordenadores do Núcleo de Sociologia da Cultura (USP). Pós-doutorado na Universidade Nacional de Quilmes (UNQ/AR).

\section{Bibliografia}

BARBOSA, Francisco de Assis. (1988). Verdes anos de Sérgio Buarque de Holanda. Ensaio sobre sua formação intelectual até Raízes do Brasil. In: NOGUEIRA, Arlinda Rocha; PACHECO, Floripes de Moura; PILNIK, Márcia; HORCH, Rosemarie Erika. (org.). Sérgio Buarque de Holanda: vida e obra. São Paulo: Secretaria de Estado da Cultura/USP/IEB, pp. 27-54.

BASTOS, Elide Rugai. (2016). Um livro entre duas Constituintes. In: HOLANDA, Sérgio Buarque de. Raizes do Brasil: edição crítica. São Paulo: Companhia das Letras, pp. 405-410. 
BLANCO, Alejandro; JACKSON, Luiz Carlos. (2014). Sociologia no espelho: ensaístas, cientistas sociais e críticos literários no Brasil e na Argentina (19301970). São Paulo: Editora 34.

CANDIDO, Antonio. (1982). Sérgio em Berlim e depois. Novos Estudos Cebrap, v. 1, n. 3, pp. 4-9.

CANDIDO, Antonio. (1990). Radicalismos. Estudos Avançados, v. 4, n. 8, pp. 4-18.

CANDIDO, Antonio. (2016). O significado de Raízes do Brasil. In: HOLANDA, S. B. Raizes do Brasil. São Paulo: Companhia das Letras, pp. 355-369.

CITELLI, Adilson. (2010), "Um operário em (des) construção". Comunicação e Educação, ano XV, no2, pp.125-134.

BARBOSA, Ir. João Batista. (2013). Breve História do Colégio de São Bento de São Paulo (1903-2013). Livro 110 anos do Colégio São Bento. Colégio São Bento, 2 set. 2013. Disponível em: https://bit.ly/3Dv6yi4. Acesso em: 11/6/2015.

FERNANDES, Florestan. (1949). Raízes do Brasil. Revista do Arquivo Municipal, nº CXXII, pp. 222-224.

FREYRE, Gilberto. (2006a). Casa-grande E̋ senzala. São Paulo: Global. 350 FREYRE, Gilberto. (2006b). Sobrados e mucambos. São Paulo: Global. GRAHAM, Richard. (1982). Entrevista com Sergio Buarque de Holanda. Ciência e cultura, v. 34, n. 9, pp. 1175-1182.

HOLANDA, Sérgio Buarque de. (1936). Raízes do Brasil. Rio de Janeiro: Livraria José Olympio Editora.

HOLANDA, Sérgio Buarque de. Raizes do Brasil. (1948). Rio de Janeiro: Livraria José Olympio Editora.

HOLANDA, Sérgio Buarque de. (2016). Raízes do Brasil: edição crítica. São Paulo: Companhia das Letras.

HOLANDA, Bartolomeu Buarque de. (2007). Buarque: uma família brasileira. Ensaio histórico-genealógico. Rio de Janeiro: Casa da Palavra. HOLANDA, Maria Amélia Buarque de. (2006). Apontamentos para cronologia de Sergio Buarque de Holanda. In: HOLANDA, Sergio Buarque de. Raízes do Brasil. Edição comemorativa 70 anos. São Paulo: Companhia das Letras, pp. 421-446.

IGLESIAS, Francisco. (2009). História e literatura: ensaios para uma história das ideias no Brasil. São Paulo: Perspectiva.

JACKSON, Luiz Carlos. (2007). Tensões e disputas na sociologia paulista (1940-1970). Revista Brasileira de Ciências Sociais, v. 22, n. 65, pp. 33-49. DOI: 10.1590/S0102-69092007000300004 
LEITE, Dante Moreira. (1983). O caráter nacional brasileiro: história de uma ideologia. 4- ed. São Paulo: Pioneira.

MICELI, Sergio. (2012). Intelectuais à brasileira. São Paulo: Companhia das Letras.

MONTEIRO, Pedro Meira. (1999). A queda do aventureiro: aventura, cordialidade e os novos tempos em 'Raizes do Brasil'. Campinas: Editora da Unicamp.

MONTEIRO, Pedro Meira; SCHWARCZ, Lilia Moritz. (2016). Uma edição crítica de 'Raízes do Brasil': O historiador lê a si mesmo. In: HOLANDA, Sérgio Buarque de. Raízes do Brasil. São Paulo: Companhia das Letras, pp. 11-26.

MORAES, Monica Isabel de. (2017). Duas raizes: o ensaísmo de Sérgio Buarque de Holanda. Dissertação de mestrado em Sociologia. São Paulo: USP. DOI: 10.11606/D.8.2017.tde-09062017-115851

MOTA, Carlos Guilherme. (2014). Ideologia da cultura brasileira (19331974). Pontos de partida para uma revisão histórica. São Paulo: Editora 34.

QUEIROZ, Maria Isaura Pereira de. (1957). Resenha de Raízes do Brasil. Suplemento Literário do O Estado de S. Paulo, 27 abr. 1957, pp. 2. Disponível em: https://bit.ly/3zzGX5d. Acesso em: 30 ago. 2021.

RODRIGUES, Lidiane Soares. (2011). A produção social do marxismo universitário em São Paulo: mestres, discípulos e 'um seminário' (19581978). Tese do doutorado em História Social. São Paulo: USP.

DOI: 10.11606/T.8.2012.tde-05072012-164401

ROCHA, João Cezar de Castro. (2012). Raízes do Brasil: Biografia de um Livro-problema. In: MARRAS, Stelio. (org.). Atualidade de Sérgio Buarque de Holanda. São Paulo: Edusp, pp. 19-37.

SALLUM JR., Brasilio. (2012). Sobre a noção de democracia em Raizes do Brasil. In: MARRAS, Stelio. (org.). Atualidade de Sérgio Buarque de Holanda. São Paulo: Edusp, pp. 51-61.

SERRANO, Paulo. (2016). A crítica bandeirante (1920-1950). Dissertação de mestrado em Sociologia. São Paulo: USP. DOI: 10.11606/D.8.2016. tde-21122016-131649

SORÁ, Gustavo. (2010). Brasilianas: José Olympio e a Gênese do Mercado Editorial Brasileiro. São Paulo: Edusp.

WAIZBORT, Leopoldo. (2011). O mal-entendido da democracia: Sérgio Buarque de Hollanda, Raízes do Brasil, 1936. Revista Brasileira de Ciências Sociais, v. 26, n. 76, pp. 39-62. Disponível em: https://bit.ly/3Bl2Plg. Acesso em: 30 ago. 2021

WEGNER, Robert. (2000). A conquista do Oeste: a fronteira na obra de Sérgio Buarque de Holanda. Belo Horizonte: Ed. UFMG. 
Açúcar e café

WEGNER, Robert. (2006). Um ensaio entre o passado e o futuro. In: HOLANDA, Sérgio Buarque de. Raízes do Brasil. Edição comemorativa 70 anos. São Paulo: Companhia das Letras, pp. 335-364.

WEGNER, Robert. (2009). Caminhos de Sérgio Buarque de Holanda. In: BOTELHO, André; SCHWARCZ, Lilia Moritz. (org.). Um enigma chamado Brasil. São Paulo: Companhia das Letras, pp. 212-225. 


\section{AÇÚCAR E CAFÉ: AMBIGUIDADE DE RAÍZES DO BRASIL}

\section{LUIZ CARLOS JACKSON}

MONICA ISABEL DE MORAES

Resumo: O objetivo principal deste artigo é discutir a dimensão política de Raízes do Brasil, objeto de debate recente. Abordamos esse problema por meio de uma reconstrução sucinta da trajetória de Sérgio Buarque de Holanda, que teria, possivelmente, condicionado seu posicionamento. Entendemos que Sérgio Buarque não fixou em Raízes do Brasil uma mensagem política unívoca e sugerimos que o livro conteria um argumento central com desfecho ambíguo, cuja gênese teria relação com a ambivalência da origem social e geográfica de seu autor.

Palavras-chave: Intelectuais; Sérgio Buarque de Holanda; Origem Familiar; Trajetória; Raízes do Brasil.

\section{SUGAR AND COFFEE: THE AMBIGUITY OF RAÍZES DO BRASIL}

Abstract: This study primary goal is to discuss the political dimension of Raizes do Brasil (Roots of Brazil), a subject of recent controversy. Such issue is approached through a brief reconstruction of the trajectory of Sérgio Buarque de Holanda, which might have had shaped his position. We understand that Sérgio Buarque did not fix a univocal political message in Raizes do Brasil, suggesting that the work contains a central argument with an ambiguous outcome whose genesis would be related to the ambivalence of the social and geographic origin of the author.

Keywords: Intelectuals; Family Origin; Sérgio Buarque De Holanda; Trajectory; Raízes Do Brasil.

Recebido: 21/01/2020

Aprovado: 26/07/2021 